\title{
Avaliação do desempenho hidráulico da bomba injetora Indek, para fertigação
}

\author{
André L. T. Fernandes ${ }^{1}$, Rubens D. Coelho ${ }^{2} \&$ Tarlei A. Botrel ${ }^{2}$ \\ 1 Universidade de Uberaba, Instituto de Ciências e Tecnologia do Ambiente. Av. Nenê Sabino 1801, CEP 38055-500, \\ Uberaba, MG. Fone: (34) 3319-8963. E-mail: andre.fernandes@uniube.br (Foto) \\ 2 Depto. de Engenharia Rural, ESALQ/USP. Av. Pádua Dias 11, Piracicaba, SP. Fone: (19) 3429-4217, Ramal: 223
}

Protocolo 37 - 24/2/2003 - Aprovado em 29/8/2003

\begin{abstract}
Resumo: Para que se possa obter bom rendimento das culturas, torna-se necessário o fornecimento de água e nutrientes às plantas. A prática que faz a aplicação simultânea de água e nutrientes ou defensivos, é denominada quimigação e, para sua utilização racional, é essencial o conhecimento das características dos equipamentos utilizados. Este trabalho teve como objetivo avaliar o desempenho hidráulico da bomba injetora de fertilizantes da marca Indek, visando ao desenvolvimento e a calibração de um modelo matemático que relacionasse as condições de operação (regulagens do curso do êmbolo da bomba, pressão na linha de injeção e pressão de sucção) com a vazão de injeção de fertilizantes no sistema de irrigação. Através de ensaios em laboratório, simulando condições de campo, obtiveram-se os valores de vazão final injetada a partir dos quais se elaborou um modelo matemático, o qual estimou satisfatoriamente a vazão injetada pela bomba, em diversos pontos de regulagem do sistema injetor. $\mathrm{O}$ modelo proposto ajustou-se bem às regulagens do êmbolo de 20,30 e $40 \mathrm{~mm}$. Na regulagem de $10 \mathrm{~mm}$, não se obteve boa correlação entre os valores estimados e os observados de vazão de injeção.
\end{abstract}

Palavras-chave: quimigação, injetores, modelo matemático

\section{Hydraulic performance of Indek injection pump for fertigation}

\begin{abstract}
In order to obtain good yields of crops, the supply of water and nutrients is essential to plants. A practice that makes the simultaneous application of water and nutrients or agricultural chemicals is called quimigation and its rational use, depends on complete knowledge of the hydraulic performance of the injection system. This study intended to evaluate the hydraulic performance of a injector pump of fertilizers (Indek) with the development and the calibration of a mathematical model to relate the operational conditions (tuning of the course of the pump's pistols, injection and suction pressure) with injection of fertilizers in irrigation systems. Through trials in the laboratory, simulating field conditions, the values of final flow injected were obtained and a mathematical model was elaborated, which estimated the flow of the solution injected satisfactorily at various points of injecting system. The proposed model had better performance for the piston regulations of 20,30 and $40 \mathrm{~mm}$. For the regulation of $10 \mathrm{~mm}$, good correlation was not obtained among the estimated and observed values of injection flow.
\end{abstract}

Key words: quimigation, injector mechanisms, mathematical model

\section{INTRODUÇÃO}

Para que se tenha bom rendimento das culturas, é imprescindível o fornecimento de água e nutrientes às plantas. Uma prática que faz a aplicação simultânea de água e fertilizantes ou defensivos passou a ser utilizada gradativamente no Brasil, a fim de que os inconvenientes de uma aplicação separada dos produtos pudessem ser diminuídos. Esta técnica é chamada quimigação e seu objetivo básico é utilizar a água de irrigação como veículo para a condução dos nutrientes e defensivos necessários ao adequado desenvolvimento das plantas, assim como proteção e combate às doenças, pragas e plantas daninhas. Quando os produtos aplicados via água de irrigação são fertilizantes, a técnica é denominada fertigação. Segundo Papadopoulos (1999), o melhoramento da eficiência no uso da água e dos fertilizantes pelos agricultores constitui o principal fator para garantir o aumento da produção de alimentos e reverter a degradação ambiental, ou evitar os irreversíveis danos ambientais. Para a utilização racional da fertigação, é essencial o conhecimento de características técnicas dos equipamentos 
utilizados, para posterior calibração dos mesmos no campo. Os sistemas de aplicação de fertilizantes via água de irrigação podem ser classificados em: a) tubo ligado à sucção da bomba ou aplicação por pressão negativa (Vieira, 1988; Zanini \& Olitta, 1989): através de um tubo conectado à tubulação de sucção de água, a solução é succionada, passando pela bomba de irrigação; b) sistemas baseados na pressão diferencial: o princípio desses sistemas consiste em se provocar ou aproveitar uma diferença de pressão entre dois pontos na rede de irrigação, fazendo com que parte do fluxo de água escoe entre eles, passando através do tanque de fertilizante e diluindo a solução, a qual vai sendo injetada no sistema. Muitas são as formas de se promover ou se utilizar a diferença de pressão para fins de aplicação de fertilizantes surgindo, conseqüentemente, os vários sistemas existentes, como tanque de derivação de fluxo, tanque de corrente direta e aplicadores com tubo pitot; c) bombas injetoras (Frizzone et. al., 1985; Zanini, 1989; Vieira, 1988; e Zanini \& Olitta, 1989): consiste em se injetar a solução existente em um tanque aberto na rede de irrigação, por meio de uma bomba apropriada. As bombas podem ser do tipo diafragma, pistão ou centrífugas acionadas pela própria pressão de água por motores elétricos ou por combustão (Vieira, 1988).

Segundo Costa \& Brito (1994), o funcionamento de uma bomba injetora de pistão se dá através de movimentos sequenciados que promovem impactos consecutivos de admissão e compressão. $\mathrm{Na}$ admissão, ocorre a entrada do líquido no interior do cilindro através da válvula de sucção. Com a compressão, o líquido é direcionado para o interior da linha de descarga através da válvula de descarga. Este equipamento, de acordo com Yague (1994), é mais caro que os tanques de fertilizantes e os injetores tipo venturi, embora seja mais preciso. Pizarro (1986) discorre que a principal vantagem de bombas elétricas de pistão é a possibilidade de regulagem da vazão injetada, recomendando sua construção com materiais não corrosivos.

Também a respeito de bombas injetoras, Zanini (1989) descreve que existem dois tipos principais de bombas injetoras de fertilizantes: a) bombas operadas por uma fonte de energia, independente da bomba de irrigação, e b) bombas acionadas por meio da própria pressão da água no sistema de irrigação. Segundo o autor, as bombas injetoras são bastante utilizadas, pois mantém constante a taxa de injeção de uma calda armazenada em tanque de abastecimento, com pouca necessidade de recarga. Por outro lado, devem ser consideradas algumas desvantagens, como: o equipamento é relativamente caro quando comparado com outros equipamentos de fertigação; muitos tipos requerem fonte de energia; a injeção prosseguirá em casos de interrupção do fluxo de água, exceto para bombas acionadas hidraulicamente.

De acordo com Almeida (2002), as bombas injetoras com motor elétrico estão muito difundidas porque são utilizadas não somente para a injeção de fertilizantes, mas, também, nos tratamentos de água, na indústria petroquímica, na indústria, etc. Nos modelos mais usados, ainda conforme o autor, a pressão de injeção varia entre 400 e $1200 \mathrm{kPa}$, e os volumes injetados variam entre 1 e $1500 \mathrm{~L} \mathrm{~h}^{-1}$.
Segundo Frizzone et. al. (1985), deve-se levar em conta alguns critérios para uma escolha adequada: a) volume e capacidade do equipamento: em função da quantidade de solução que o tanque pode conter e a vazão a ser injetada na rede de irrigação; b) fidelidade de funcionamento: este critério está relacionado à precisão do equipamento, sua resistência em condições de campo, nível técnico e capacidade exigida do operador, necessidade de acompanhamento no início e término da operação e qualidade da assistência técnica; c) funcionamento: refere-se à fonte de energia para o equipamento de fertigação; d) mobilidade: em propriedades agrícolas com grande número de setores, deve-se preferir um equipamento móvel, o que possibilita uma redução de custos; e) diluição do fertilizante: a proporção de diluição é a relação entre a quantidade de solução de fertilizante e a quantidade total.

Analisando-se e seguindo com cuidado esses critérios, torna-se possível uma escolha adequada do tipo de equipamento a ser utilizado, proporcionando então uma aplicação eficiente de fertilizantes ou defensivos via água de irrigação.

Vários são os fatores que influenciam na eficiência de um sistema de fertirrigação, dentre os quais se destaca o desempenho hidráulico dos injetores. Segundo Dourado Neto et al. (2001), a regulagem de uma bomba injetora é feita em função da informação do fabricante, ou de uma calibração feita pelo usuário em condições reais de funcionamento no campo; esta última é a mais recomendada, devido à normal variação de vazão devido a desuniformidade de fabricação dos equipamentos.

Esse trabalho teve como objetivo analisar o desempenho hidráulico da bomba injetora de produtos químicos da marca nacional INDEK, visando o desenvolvimento e a calibração de um modelo matemático que relacionasse as condições de operação e regulagens do mecanismo injetor com a vazão de injeção da solução no sistema de irrigação.

\section{MATERIAL E MÉTODOS}

O ensaio da bomba injetora por acionamento elétrico foi realizado nas dependências do Laboratório de Hidráulica do Departamento de Engenharia Rural da Escola Superior de Agricultura Luiz de Queiroz - USP, Piracicaba - SP. Os materiais utilizados no ensaio foram:

a) Tanque volumétrico, graduado em $\mathrm{dm}$, com capacidade de $1200 \mathrm{~L}$;

b) Manômetro de Bourdon;

c) Vacuômetro com líquido indicador de Mercúrio;

d) Voltímetro e amperímetro;

e) Conjunto motobomba KSB, Modelo 80/5;

f) Vazão: $40 \mathrm{~m}^{3} \mathrm{~h}^{-1}$; Altura manométrica: $100 \mathrm{kPa} ; 1750$ rotações $\min ^{-1}$;

g) Bomba injetora dosadora INDEK (Figura 1), Modelo BP238, 1725 RPM; 2 CV - Motor Kolbach (trifásico), 1730 rotações min $^{-1}, 2 \mathrm{CV}$ : este modelo trabalha com vazão de 295 a $840 \mathrm{~L} \mathrm{~h}^{-1}$, nas pressões de operação de 5 a $15 \mathrm{kgf} \mathrm{cm}^{-2}$, com escala de ajuste de vazão de 15 a 40 mm;

h) Linha pressurizadora (simulação do sistema de irrigação). 


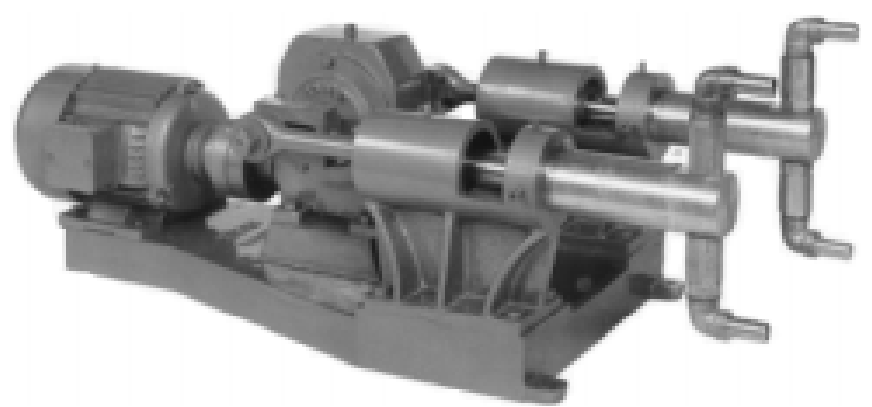

Figura 1. Bomba injetora dosadora INDEK

A disposição dos materiais no local de ensaio pode ser vista na Figura 2.

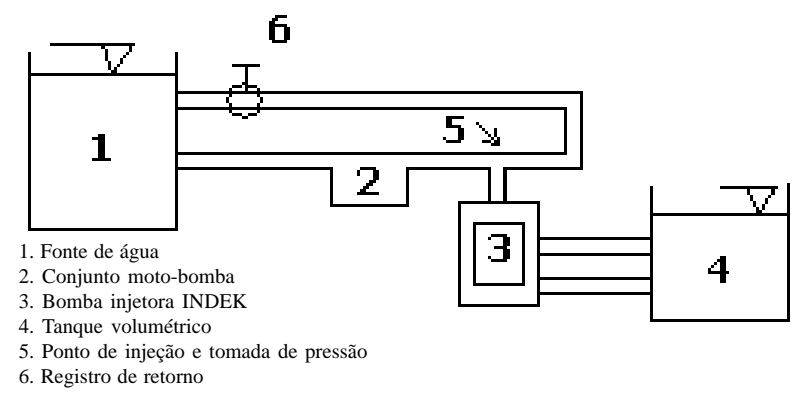

Figura 2. Esquema da conexão dos equipamentos no local de ensaio

Foi adotado o seguinte procedimento para a coleta de dados no ensaio:

- acionamento do conjunto motobomba centrífuga para pressurização da linha, onde um registro de retorno proporciona diferentes ajustes de pressão, simulando a tubulação de irrigação que recebe a solução de fertilizante;

- acionamento da bomba injetora dosadora INDEK;

- abertura do registro de retorno para estabilizar a pressão de ensaio (leitura do manômetro);

- ajuste da pressão de sucção de ensaio através do registro instalado na tubulação de sucção (leitura do vacuômetro);

- leitura da voltagem e amperagem bem como da rotação do motor da bomba injetora para posterior utilização no cálculo da porcentagem de enchimento da referida bomba;

- anotação do nível de água no tanque volumétrico no início e no final de 5 min (através dessas leituras, obtidas no tanque volumétrico graduado, foi determinada a vazão da bomba, pelo fato da mesma promover a sucção da água do tanque).

Os procedimentos se repetiram para cada quatro regulagens do curso do êmbolo da bomba (10, 20, 30 e $40 \mathrm{~mm})$ combinadas com cinco pressões no ponto de injeção $(0 ; 195,94 ; 391,87$; 587,81 e $783,75 \mathrm{kPa}$ ) e as possíveis regulagens da intensidade de sucção $(0 ; 13,34 ; 26,67 ; 40,00 ; 53,32$ e $66,62 \mathrm{kPa})$. Esta variação da intensidade de sucção da bomba simula condições reais de campo.

A partir dos dados coletados, propôs-se um modelo matemático cujo principal objetivo foi o de calcular, de maneira rápida e eficiente, a quantidade de solução injetada pela bomba INDEK ensaiada nas diversas combinações entre o curso do êmbolo e pressão na linha de injeção de sucção. O modelo permite, portanto, calcular a vazão injetada de uma solução de água e fertilizantes ou defensivos, num sistema qualquer de irrigação. Este cálculo de vazão depende de algumas variáveis de entrada: do volume teórico do êmbolo da bomba; da porcentagem de enchimento do cilindro e da rotação do motor que aciona a bomba. A porcentagem de enchimento do cilindro da bomba injetora é um indicativo da harmonia mecânica do conjunto (abertura de válvulas e perdas de cargas localizadas no sistema hidráulico). Durante o percurso do êmbolo, nem sempre se alcança uma eficiência no enchimento de $100 \%$, ou seja, nem sempre o cilindro está totalmente preenchido com a solução a ser injetada.

Com essas variáveis citadas, elaborou-se modelo matemático do tipo (Eq. 1):

$$
\mathrm{V}=\mathrm{VT} \times \% \mathrm{E} \times \mathrm{CPM} \times 2 \times 60
$$

em que:

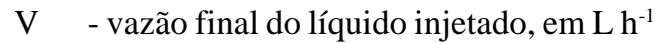

$\%$ E - porcentagem de enchimento do cilindro da bomba

CPM - número de ciclos do êmbolo por minuto

VT - volume teórico do êmbolo da bomba

A multiplicação por 2 na Eq. (1) é devido à bomba ensaiada apresentar 2 cilindros; o número de ciclos por minuto de cada êmbolo foi estimado indiretamente pela rotação do motor elétrico, levando-se em consideração a relação de transmissão (1:20) do elemento redutor de velocidade existente entre o motor elétrico e a bomba; o software utilizado para a análise estatística foi o MINITAB.

\section{RESULTADOS E DISCUSSÃO}

Com os dados de pressão na linha de injeção e vazão do líquido injetado, elaboraram-se gráficos para os diferentes cursos do êmbolo da bomba (Figura 3). Observou-se, no decorrer do experimento, que nem sempre é possível estabilizar a pressão de sucção no valor desejado, devido ao tipo de mecanismo na bomba injetora analisada (pistões); por esta razão, os níveis do curso do êmbolo nem sempre foram ensaiados nas mesmas pressões de sucção ocorrendo, portanto, variações entre os diferentes cursos.

Observando-se os dados plotados na Figura 3A, referentes ao curso de $10 \mathrm{~mm}$, fica evidente que a capacidade de injeção da bomba reduz com o aumento da pressão na linha de injeção. Ocorre uma diminuição de vazão injetada e queda na porcentagem de enchimento. Os resultados de vazão obtidos ficaram dentro da faixa estipulada por Almeida (2002) como fato comum para bombas injetoras, ou seja, de 1 a $1500 \mathrm{~L} \mathrm{~h}^{-1}$, dependendo do tipo de bomba utilizada.

Nota-se, também, que a variação do pico de sucção, através do registro que simula o filtro para o mesmo curso, ocasiona uma queda na vazão do líquido injetado, tendência esta que se acentua de acordo com o aumento da pressão de sucção (aumento no grau de entupimento), já esperado.

Para a Figura 3B (curso do êmbolo de $20 \mathrm{~mm}$ ) verificou-se comportamento semelhante ao da Figura 3A, com queda de 


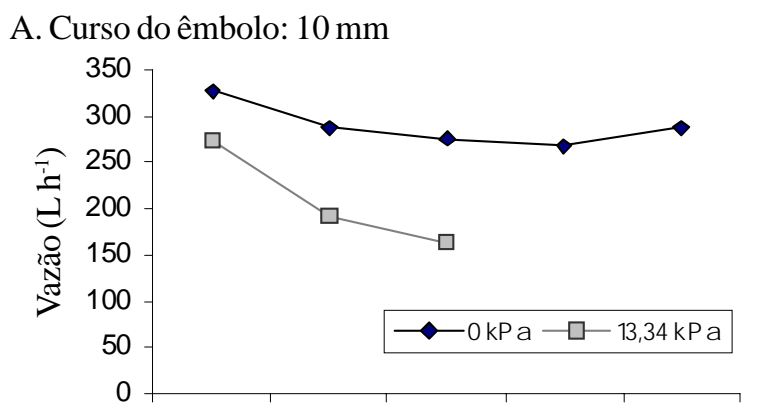

B. Curso do êmbolo: $20 \mathrm{~mm}$

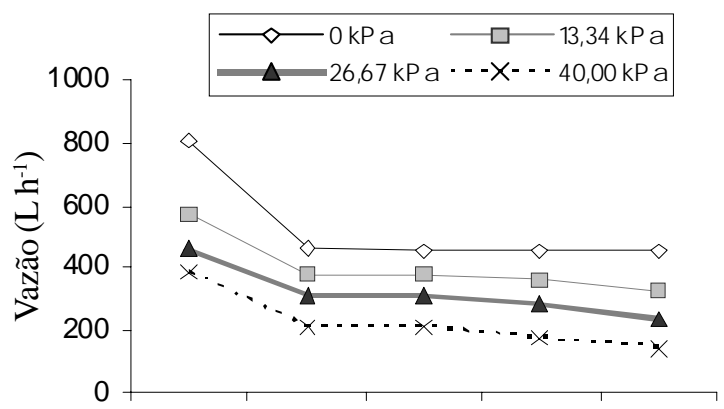

C. Curso do êmbolo: $30 \mathrm{~mm}$
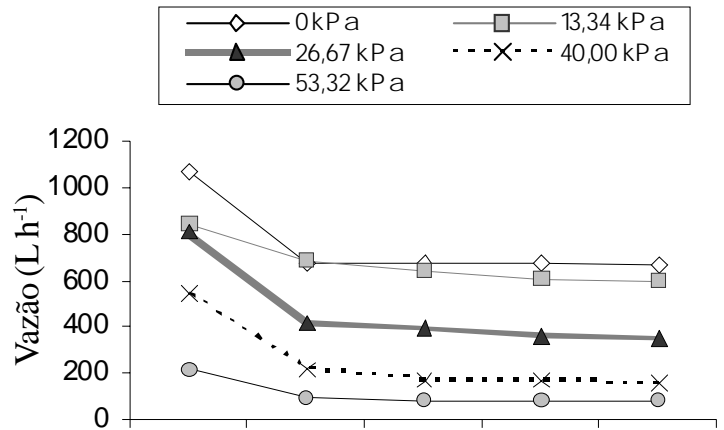

D. Curso do êmbolo: $40 \mathrm{~mm}$

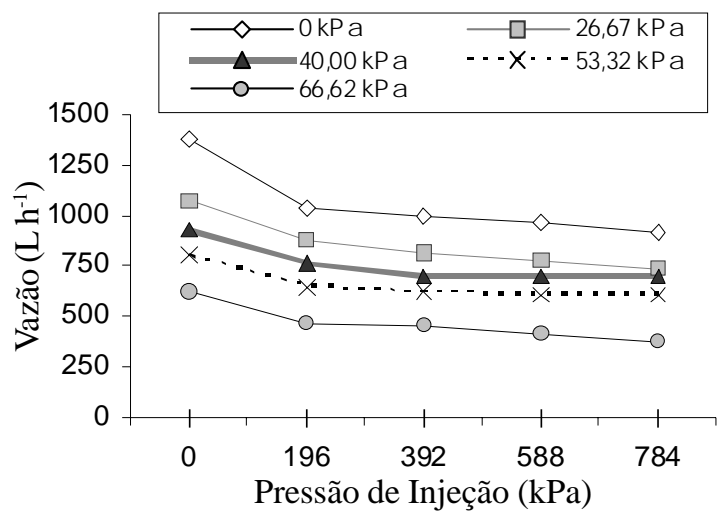

Figura 3. Vazão da bomba injetora INDEK, para os cursos de 10, 20, 30 e 40 mm, em diferentes pressões de injeção e sucção

vazão e diminuição da porcentagem de enchimento da bomba à medida que aumentava a pressão na linha de injeção e de sucção. Apesar desse comportamento se mostrar idêntico ao curso de $10 \mathrm{~mm}$, verificou-se um aumento da vazão do líquido injetado, devido ao curso maior do êmbolo da bomba injetora $20 \mathrm{~mm}$, que promove maior injeção de líquido na linha de irrigação, comparado com o de $10 \mathrm{~mm}$.

O comportamento da bomba também se repetiu para os outros dois cursos ensaiados ( 30 e $40 \mathrm{~mm}$ ) conforme pode ser observado nas Figuras 3C e D; por sua vez, a bomba se mostrou mais eficiente nas maiores regulagens do curso do êmbolo, onde se observaram aumentos na vazão da solução injetada e na porcentagem de enchimento do êmbolo da bomba.

Comparando-se os dados referentes à rotação do motor que aciona a bomba, voltagem e amperagem entre as diferentes regulagens de curso do êmbolo, não se verificou diferença expressiva entre eles.

Com os resultados experimentais obtidos, ajustou-se uma equação para a porcentagem de enchimento do cilindro da bomba, através de uma regressão múltipla. Convêm salientar que para a elaboração dessa equação, foram analisadas estatisticamente todas as possibilidades de combinação entre as variáveis utilizadas, a fim de que fosse possível a escolha de uma equação geral que proporcionasse segurança nos cálculos posteriores. Utili-zouse, na equação proposta uma combinação de todas as variáveis (pressão de injeção, pressão de sucção e curso do êmbolo) e seus respectivos quadrados, pelo fato dessa combinação apresentar o maior coeficiente de determinação observado. A equação encontrada foi a seguinte:

$$
\begin{aligned}
\% \mathrm{E}= & 37,8-1,16 \mathrm{P}+3,67 \mathrm{C}-0,144 \mathrm{~S}-0,000016 \mathrm{~S}^{2}+ \\
& 0,00967 \mathrm{P}^{2}-0,0296 \mathrm{C}^{2}
\end{aligned}
$$

em que:

$\% \mathrm{E}$ - porcentagem de enchimento da bomba

C - curso do êmbolo da bomba, em mm

$\mathrm{P}$ - pressão na linha de injeção, em mca

S - pressão de sucção, em mm Hg

Com a combinação entre as variáveis utilizadas, o valor do coeficiente de correlação foi de 0,731 . Mesmo com o emprego da melhor combinação, o coeficiente encontrado não se mostrou adequado, o que pode ser atribuído à tendência distinta dos dados relativos a cada variável estudada.

Para o ajuste do volume teórico do êmbolo, elaborou-se, a partir de regressão, a Eq. 3, que apresentou um coeficiente de correlação $\left(R^{2}\right)$ de 0,9978 :

$$
\mathrm{VT}=7,8246+2,1895 \mathrm{C}
$$

em que:

VT - volume teórico do êmbolo da bomba;

C - curso do êmbolo da bomba, em $\mathrm{mm}$.

A partir do modelo matemático proposto, calcularam-se para todas as regulagens do êmbolo da bomba injetora, a porcentagem de enchimento e a vazão, que então foram comparados com os valores observados em laboratório.

Na Figura 4 estão apresentadas as regressões entre os valores de vazão e enchimento obtidos experimentalmente e os valores estimados pelo modelo matemático proposto, utilizando-se todos os dados, em todas as regulagens do êmbolo da bomba. Nota-se que as melhores estimativas com o modelo proposto foram obtidas para a vazão, com um coeficiente de correlação de 0,8461 , superior ao obtido com a estimativa da \% de enchimento, com $\mathrm{R}^{2}=0,7347$. 
A.

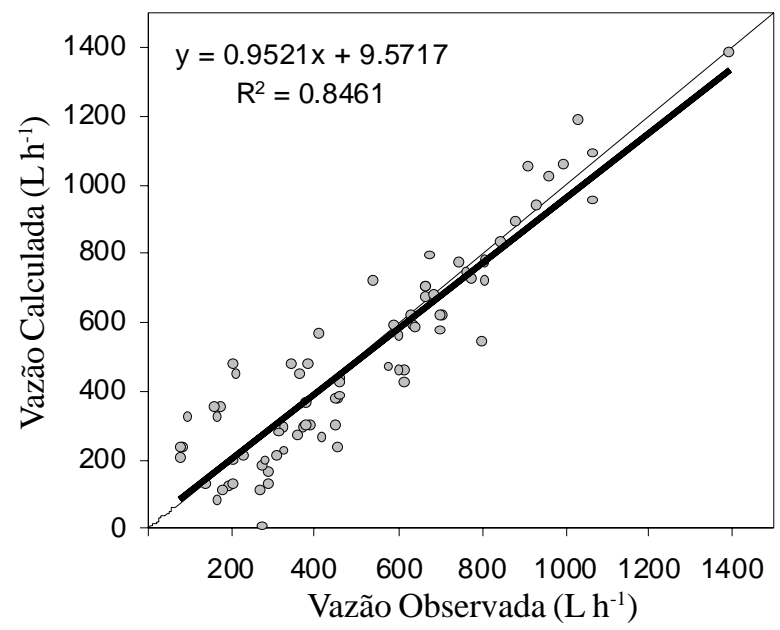

B.

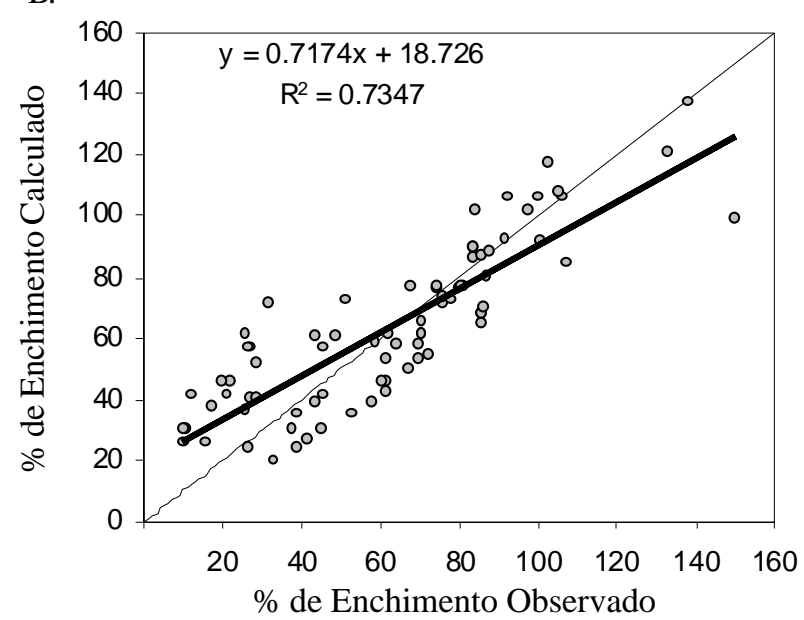

Figura 4. Análise de regressão entre os dados observados e estimados pelo modelo matemático; (A) vazão e (B) \% de enchimento

Analisando-se separadamente os valores observados e estimados para cada regulagem do êmbolo, verificam-se melhores correlações tanto para vazão quanto para a porcentagem de enchimento, na medida em que se aumentou o curso do êmbolo da bomba, conforme pode ser visto na Tabela 1 .

Analisando-se as equações da Tabela 1, observa-se que os valores de enchimento e vazão obtidos e calculados se aproximam, na medida em que a regulagem do êmbolo aumenta, ou seja, no curso de $40 \mathrm{~mm}$, por exemplo, a diferença entre os valores observados e os valores estimados é menor que nos

Tabela 1. Equações de regressão linear com os respectivos coeficientes de correlação, considerando o curso do êmbolo para a vazão injetada $\left(\mathrm{L} \mathrm{h}^{-1}\right)$ e porcentagem de enchimento

\begin{tabular}{cccc} 
& $\begin{array}{c}\text { Curso do } \\
\text { Êmbolo }(\mathrm{mm})\end{array}$ & \multicolumn{1}{c}{ Equação } & $\mathrm{R}^{2}$ \\
\hline \multirow{3}{*}{ Vazão } & 10 & $\mathrm{Y}=0,5568 . \mathrm{X}-0,2597$ & 0,2056 \\
& 20 & $\mathrm{Y}=0,7116 . \mathrm{X}-0,4943$ & 0,8524 \\
& 30 & $\mathrm{Y}=0,6825 . \mathrm{X}+3,8937$ & 0,9182 \\
\% Enchi- & 40 & $\mathrm{Y}=1,2525+3,7642$ & 0,9507 \\
mento & 10 & $\mathrm{Y}=1,9703 . \mathrm{X}-4,2103$ & 0,5794 \\
& 30 & $\mathrm{Y}=0,7078 . \mathrm{X}-5,6546$ & 0,8953 \\
& 40 & $\mathrm{Y}=0,6908 . \mathrm{X}-29,552$ & 0,9313 \\
& & $\mathrm{Y}=1,248 . \mathrm{X}-22,614$ & 0,9512 \\
\hline
\end{tabular}

cursos menores $(10,20$ ou 30) conforme pode ser visualizado na Figura 5, tanto para vazão (5A) quanto para a porcentagem de enchimento (5B).

Os valores de enchimento maiores que $100 \%$ observados na pressão de injeção de $0 \mathrm{kPa}$ (pressão atmosférica), se devem ao fato de que parte da solução água + fertilizantes passou diretamente através da bomba durante o ciclo de movimentação do cilindro (assemelhando-se a um sifão), pois em baixas pressões de injeção a vedação das válvulas existentes no mecanismo da bomba INDEK não é eficiente, o que proporciona valores de enchimento maiores que $100 \%$.

Portanto, a faixa ótima de trabalho com esse modelo é aquela que envolve as regulagens maiores do curso do êmbolo, com obtenção de coeficientes de correlação de 0,9182 e 0,9507, respectivamente para as regulagens de 30 e $40 \mathrm{~mm}$; embora não com a mesma eficiência, o modelo também se ajustou satisfatoriamente para a regulagem de $20 \mathrm{~mm}$, pelo fato das diferenças entre os valores não se mostrarem muito elevadas $\left(\mathrm{R}^{2}=0,8524\right)$.

Para o curso de $10 \mathrm{~mm}$, os dados estimados pelo modelo ficam mais dispersos em relação aos dados observados, não se recomendando, portanto, o uso do modelo para essa

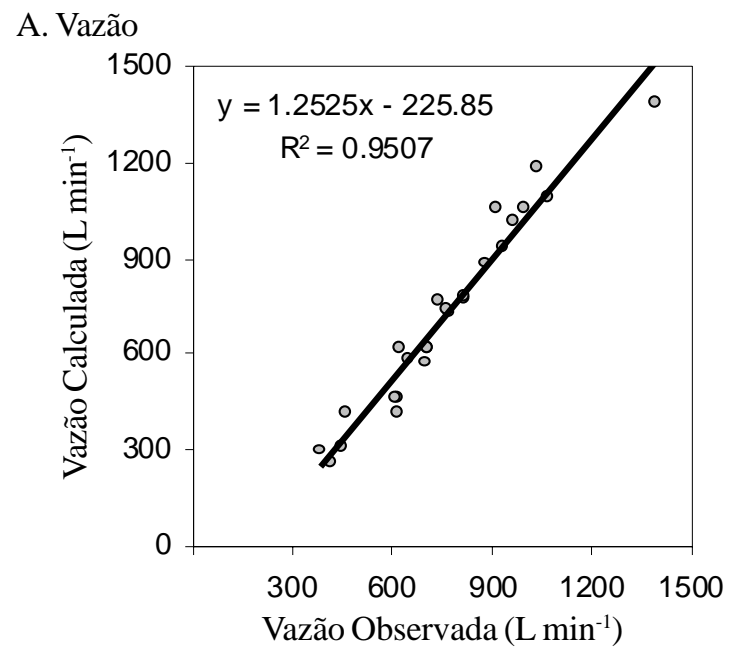

B. $\%$ de enchimento

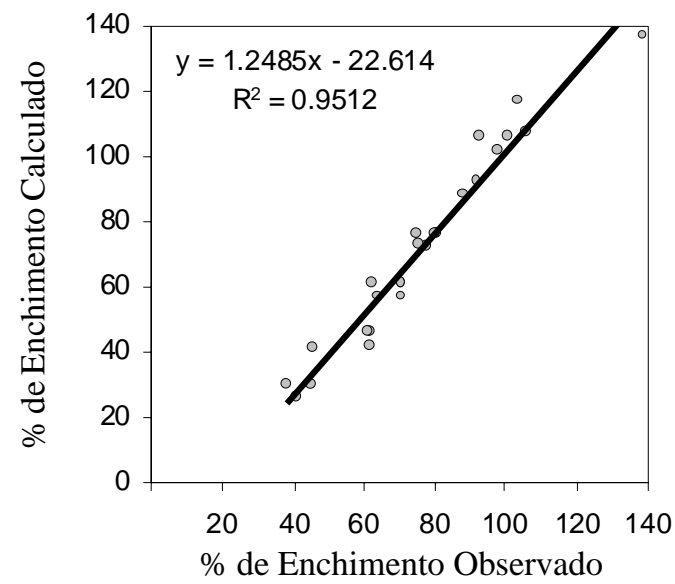

Figura 5. Comparação entre os valores de vazão observada e vazão calculada (A) e \% de enchimento observado e calculado (B), para a regulagem de $40 \mathrm{~mm}$ do êmbolo da bomba 
regulagem. Tal fato pode ser explicado pelo movimento mais curto do êmbolo da bomba nesta regulagem $(10 \mathrm{~mm})$, com pequena quantidade de solução injetada, que pode ter acarretado as maiores diferenças entre os dados observados e os calculados pelo modelo. Na Figura 6 pode ser visualizada a comparação entre os dados de vazão observados e estimados pelo modelo (6A) bem como os valores de porcentagem de enchimento observados e calculados (6B), para o êmbolo da bomba de 10 $\mathrm{mm}$. Verifica-se que não houve boa correlação, tanto para

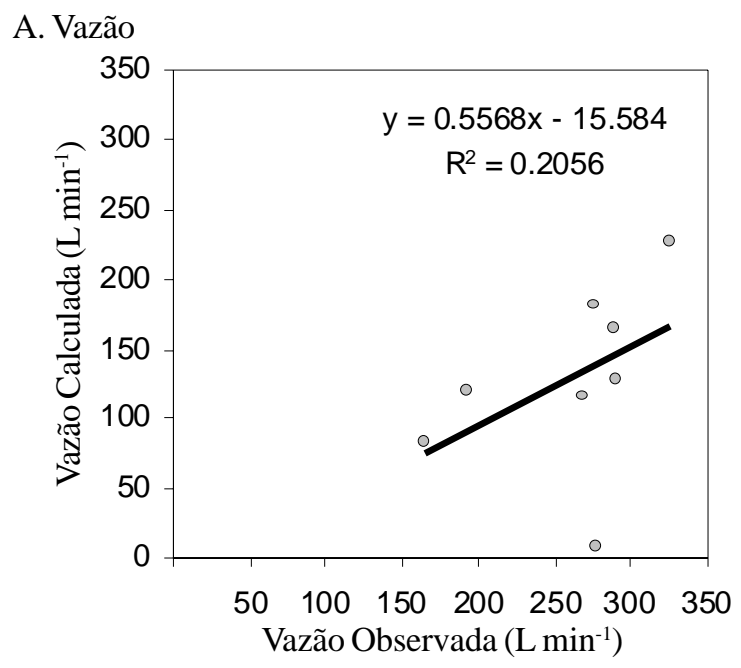

B. $\%$ de enchimento

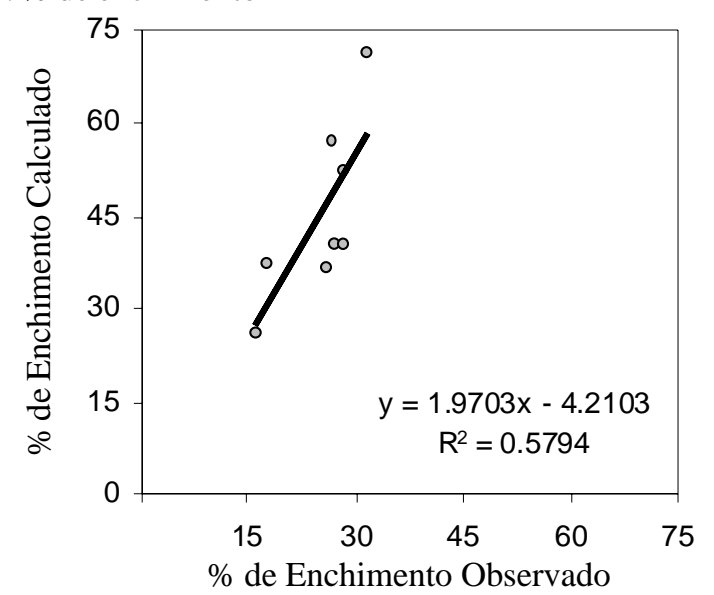

Figura 6. Comparação entre os valores de vazão observada e vazão calculada (A) e \% de enchimento observado e calculado (B), para a regulagem do êmbolo da bomba de $10 \mathrm{~mm}$ vazão, com um coeficiente de 0,20 , quanto para a porcentagem de enchimento, com um coeficiente de correlação de 0,58.

\section{CONCLUSÃO}

O modelo matemático proposto, que relaciona as condições de operação e regulagem do mecanismo injetor com a vazão de injeção da solução no sistema de irrigação, ajustou-se bem às regulagens de êmbolos maiores, não se recomendando o mesmo para a regulagem de $10 \mathrm{~mm}$.

\section{LITERATURA CITADA}

Almeida, O.Á. de. Equipamentos para injeção de fertilizantes. In: Borges, A.L.; Coelho, E.F.; Trindade, A. Fertirrigação em fruteiras tropicais. Cruz das Almas: Embrapa Mandioca e Fruticultura, 2002, p.28-42.

Costa, E.F.; Brito, R.A.L. Métodos de aplicação de produtos químicos e biológicos na irrigação pressurizada. In: Costa, E.F.; Vieira, R.F.; Viana, P.A. Quimigação: aplicação de produtos químicos e biológicos via irrigação, Brasília: EMBRAPA-SPI, p.85-109, 1994.

Dourado Neto, D.; Frizzone, J.A.; Fancelli, A.L.; Pires, R.C.M. Fertirrigação. In: Miranda, J.H.; Pires, R.C.M. (eds). Série Engenharia Agrícola, v.1, Jaboticabal: FUNEP, 2001, p.315-374.

Frizzone, J.A.; Zanini, J.R.; Dias Paes, L.A.; Nascimento, V.M. Fertirrigação mineral. Ilha Solteira: UNESP, 1985, 31p. Boletim Técnico, 2

Papadopoulos, I. Fertirrigação: situação atual e perspectivas para o futuro. In: Folegatti, M.V. Fertirrigação - citrus, flores e hortaliças, Guaíba: Agropecuária, 1999, p.11-84.

Pizarro, F. Riegos localizados de alta frequencia; Madrid: Mundi Prensa, 1986, 460p.

Vieira, D.B. Fertirrigação e manejo de irrigação em citrus, Irrigação e Tecnologia Moderna, Brasília, n. 33, p. 35-36, 1988.

Yague, J.L.F. Técnicas de riego. Madrid: Mundi-Prensa, 3 ed., 1994, 471p.

Zanini, J.R. Hidráulica da fertirrigação por gotejamento utilizando tanque de derivação de fluxo e bomba injetora. Piracicaba: ESALQ, 1989, 103p. Tese Doutorado

Zanini, J.R.; Olitta, A.F.L. Aplicação de fertilizantes com bomba injetora na fertirrigação por gotejamento. Irrigação e Tecnologia Moderna, Brasília, n.36, p.21-24, 1989. 